\title{
BURGUESÍA COMERCIAL CON ORIENTACIÓN FINANCIERA: FAMILIAS DE ARRENDATARIOS DE RENTAS EN LEÓN (1750-1850)
}

\author{
Juan Manuel BARTOLOMÉ BARTOLOMÉ
}

\begin{abstract}
RESUMEN: Estudio de familias de comerciantes leoneses que durante el periodo 1750-1850 se dedicaron a la importante actividad financiera de arrendatarios de rentas (eclesiásticas, civiles) y prestamistas de cereales o de dinero sobre todo a campesinos de los pueblos próximos a la ciudad leonesa Además, con la particularidad de que estas familias se unieron sólo a nivel de negocios formando interesantes compañías y no emparentaron entre ellas.
\end{abstract}

PALABRAS CLAVE: familias, León, comercio, finanzas, compañías, estrategias.

ABSTRACT: This is a study of merchant families from Leon betwen 1750 and 1850 an their financier activity in order to rent taxes an to lend peasants some moneny and cereals. All this has been done in a particular way. These families developed significant companies, which financier interests were involved, but they dindn't have family strategies.

KEYWORDS: families, León, merchants, financier activity, companies, strategies.

El tema que abordamos a pesar de su importancia no ha merecido demasiada atención en el panorama historiográfico leonés. Quizás la no presencia de libros de contabilidad o de caja de dichas familias expliquen ese escaso interés por el mismo. Sin embargo, estimamos que es necesario acercarnos a esa relevante actividad financiera, de arrendatarios de rentas y prestamistas de cereales o de dinero, desempeñada por una serie de familias leonesas durante la primera mitad del siglo XIX, las cuales van a unirse en los negocios mediante la formación de compañías, sin que ello implique el abandono de sus negocios comerciales, los cuales servirán de base para el desempeño de las operaciones financieras. No se tratará, por lo tanto, de actividades financieras de gran escala ${ }^{1}$, pero sí muy relevantes para

${ }^{1}$ Como las apreciadas en la familia Salinas-Fernández Llamazares y propias del primer establecimiento bancario leonés. Para mayor información sobre las mismas ver BARTOLOMÉ, J.M. 
poder desentrañar los entresijos de la economía provincial leonesa de la primera mitad del siglo XIX

A falta de contabilidades particulares hemos recogido las transacciones que se realizaron ante los escribanos: poderes, escrituras de obligación, ventas, arrendamientos, testamentos e inventarios postmortem, completándolo con la información proveniente de los archivos parroquiales. Documentación notarial donde influye mucho el azar y no es tan privilegiada como los libros de contabilidad privada pero que es la que nos puede acercar a dar respuesta a los siguientes objetivos planteados: En primer lugar, cuáles eran los negocios financieros a los que se dedicaban dichas familias. En segundo lugar, averiguar qué tipo de actividades se acompañaban de las financieras, ya que según lo que conocemos $^{2}$, son las relacionadas con el comercio de productos variados, textiles, agrarios, etc., las que se situaban en el origen de dicha burguesía posibilitando el paso a las financieras. En tercer lugar, quiénes eran las familias leonesas implicadas y sus posibles alianzas familiares y en los negocios. En cuarto lugar, analizar la estructura de sus fortunas y sus inversiones. Y finalmente, acercarnos a sus condiciones y estilo de vida.

\section{LAS FAMILIAS CON ORIENTACIÓN FINANCIERA: TIPOS DE NEGOCIOS Y ALIANZAS}

Las familias que hemos localizado son cuatro: la primera por orden cronológico es la formada por don Antonio Puelles, natural de Tordehumos en el obispado de Palencia, el cual consiguió enlazar matrimonialmente en 1784 con una de las relevantes familias leonesas de la burguesía comercial, los Fernández Chicarro, al contraer esponsales con doña Pascuala ${ }^{3}$, hija de don Agustín Fernández Chicarro y su primer esposa doña Rafaela de la Vega ${ }^{4}$. Don Antonio Puelles se va a convertir en uno de los aliados más fieles de la los negocios familiares de los padres de su esposa y así va a formar compañía comercial con su suegro, incluso en los

"Formación y desarrollo de la burguesía financiera en León: La familia Salinas-Fernández Llamazares", (en prensa).

2 GARCÍA, J.R. (1987). Los comerciantes banqueros en el sistema bancario español. Estudios de casas de banca asturianas en el siglo XIX, Oviedo. Melón, M. A. (1992). Los orígenes del capital comercial y financiero en Extremadura. Compañias de comercio, comerciantes y banqueros de Cáceres (17773-1836). Badajoz. GARCíA, A (1976). Cádiz y el Atlántico 1717-1778. Sevilla. BARTOLOMÉ, J.M. "Formación y desarrollo de la burguesía..."

${ }^{3}$ Archivo Parroquial de San Martín (A.P.S.M.), Libro Casados $\mathrm{N}^{\circ} 5$.

${ }^{4}$ Ver BARTOLOMÉ, J.M. "La formación de un gran patrimonio mercantil-agrícola en León: la familia Fernández-Chicarro (1700-1850)", (en prensa). 
momentos más difíciles de su viudez, obteniendo sustanciosos beneficios ${ }^{5}$. Su fallecimiento se producirá a comienzos del siglo XIX, en 1816, dejando un total de ocho hijos ${ }^{6}$. La segunda familia es la de don Francisco Uriarte que se va a casar con doña Agustina Blanco teniendo un total de cuatro hijos, tres de ellos menores de edad en el momento de la muerte del padre en 1834 dejando a la madre como tutora y curadora de los mismos ${ }^{7}$. La tercera, es la constituida por don Fernando Carrillo casado con doña Paula González, el cual va a morir en 1836 quedando dos hijos de su matrimonio: doña Teresa y don Salvador ${ }^{8}$. Y la cuarta, es la familia formada por don Pedro Llamas el cual estuvo casado en primeras nupcias con doña Baltasara García y en segundas con doña Francisca Antón. Su fallecimiento se va producir en 1841 dejando un total de seis hijos'.

De las cuatro familias indicadas las tres últimas van a realizar entre sí alianzas en los negocios financieros, formación de compañías, sin que esta amistad en los negocios desemboque en uniones familiares de parentesco. Así, por una parte, los tres figurarán en el arrendamiento del Voto de Santiago de la provincia ${ }^{10}$. Por otra parte, don Francisco Uriarte y don Pedro Llamas tendrán compañía en el arrendamiento de aguardiente y licores de la provincia ${ }^{11}$. Y finalmente, don Pedro Llamas y un hijo de don Fernando Carrillo (don Salvador Carrillo) también aparecerán, junto a otros comerciantes, en el arrendamiento de puertas de la ciudad de León ${ }^{12}$.

De lo anterior se deduce que los negocios desarrollados no se limitarán sólo a las actividades comerciales sino que también las financieras tendrán una gran importancia. De este modo, junto al comercio de tienda abierta de productos variados, alpargatas, botones, etc., pero fundamentalmente de textiles y de aguardiente y licores, son las operaciones financieras las más destacas. Éstas las podemos clasificar en las siguientes: en primer lugar, el arrendamiento de rentas eclesiásticas, donde se incluyen desde el arrendamiento del Voto de Santiago de

5 Ibidem.

${ }^{6}$ De ellos van a predominar los varones, seis, siendo el mayor don Agustín. Archivo Histórico Provincial de León (A.H.P.L.), Juan de Dios Fernández, Caja 954.

${ }^{7}$ Id., Pedro Ballesteros Ginovés, Caja 1144.

${ }^{8}$ Id., Ignacio Bayón Luengo, Caja 1126.

${ }^{9}$ Tres del primer matrimonio y tres del segundo. Id., Caja 1129.

${ }^{10}$ Id., Caja 1125.

${ }^{11}$ Id., Pedro Ballesteros Ginovés, Caja 1140

12 Id., Ignacio Bayón Luengo, Caja 1129. 
varios partidos de la provincia ${ }^{13}$ hasta el arrendamiento del diezmos del obispado de Astorga ${ }^{14}$, pasando por el arrendamiento de diezmos del vino del cabildo leonés ${ }^{15}$ y el arrendamiento de la renta correspondiente al convento de San Marcos de la ciudad leonesa en el arciprestazgo de Villafáfila ${ }^{16}$. En segundo lugar, el arrendamiento de rentas civiles, donde, por un parte, tenemos el arrendamiento de aguardiente y licores de la provincia leonesa, el cual les proporcionaba aguardiente para su almacén y venta posterior al por menor y también en parte subarrendaban a cambio de dinero ${ }^{17}$. Y por otra parte, el arrendamiento del remate de los derechos de puertas de la ciudad de León ${ }^{18}$. En tercer lugar, el préstamo, mediante

${ }^{13}$ La compañía compuesta por Don Fernando Carrillo, don Pantaleón Robles, don Pedro Llamas y don Francisco Uriarte, es la encargada de arrendar el voto de Santiago de varios partidos, donde, según un poder concedido en 1834, figuran los pueblos de Castrotierra de la Valdería, Villademor de Órbigo, Quintanilla del Valle, Morales de Somoza, Valderaduey, Oteruelo de Somoza, Antoñán del Valle, Valderaduey, Herreros de Jamuz, Vilagarcía de la Vega, Villabente, Alija de los Melones, etc. Los productos agrarios obtenidos con el arrendamiento del voto de Santiago eran los que vendían mediante fiado, escrituras de obligación, a los campesinos. De ahí, que el poder referido se otorga para que se cobren las deudas contraídas. Id., Pedro Ballesteros Ginovés, Caja 1147

14 También se formó una compañía de decimales del obispado de Astorga de la que formaba parte don Fernando Carrillo y don Francisco Uriarte. En su testamento declara en una de sus cláusulas: "Con respecto a la compañía de decimales del obispado de Astorga es mi voluntad se esté a lo que digan los demás consocios y a las bases prefijadas en el asunto". Id. Caja 1144.

${ }^{15}$ En 1804 don Antonio Puelles junto con don Felipe de Villafañe arrienda los diezmos del vino de las villas de Villamañán y Gordoncillo en 10.882 reales. A esta cantidad se ha de añadir la de los rediezmos, a razón de 54 maravedíes (1,5 reales) por cada millar, según el estilo y práctica de dicha Santa Iglesia Catedral. Y se han de satisfacer estas cantidades en el próximo año de 1805 en tres tercios iguales: primero fin de enero y en éste todos los rediezmos; segundo, fin de mayo y tercero, fin de septiembre. Id. Juan García Álvarez Ocón, Caja 984.

${ }^{16}$ Don Fernando Carrillo en compañía con don Juan Antonio González, vecino de la villa de La Bañeza, y la viuda de don Francisco Blanco, habían arrendado mancomunadamente la renta perteneciente al Real Convento de San Marcos en varios partidos del arciprestazgo de Villafáfila del obispado de Astorga. Id., Ignacio Bayón Luengo, Caja 1126.

${ }^{17}$ Esta compañía estaba formada sobre todo por don Francisco Uriarte y don Pedro Llamas, los cuales en 1833 subarriendan a vecinos de Villares del Órbigo en 3.000 reales (a pagar en cuatro plazos: finales de febrero, finales de mayo, finales de agosto y finales de noviembre) los derechos de vender exclusivamente aguardiente y licores al por menor hasta en la medida de medida arroba en los pueblos del partido de Villares del Órbigo durante el año próximo de 1834. También subarrendarán a vecinos de Espinosa de la Rivera por 1.300 reales por vender en el partido de San Román de los Caballeros y a vecinos de Debesa del Curueño en 810 reales por vender en los pueblos del Barrillo del Curueño. Id. Pedro Ballesteros Ginovés, Caja11144.

${ }^{18}$ En 1841 se constituye una sociedad, formada por los principales hombres de negocios de la ciudad: don Pedro Llamas, don Pantaleón Ramos, don Miguel Fernández Banciella, don Pantaleón de Robles, don Antonio Álvarez Reyero, don Mariano Jolís. don José Selva, don Salvador Carrillo, don 
escrituras de obligación, de grano a campesinos de los pueblos próximos (Armunia, Trobajo del Camino, etc.) en los meses de sementera a cambio del pago en dinero durante el mismo año bien en dos plazos (mitad en San Juan de junio y la otra mitad el 8 de septiembre) o bien en uno sólo el 8 de septiembre o por San Miguel de Septiembre ${ }^{19}$. En cuarto lugar, también prestarán dinero a vecinos, y sobre todo campesinos de los pueblos limítrofes, mediante el sistema de obligaciones. Generalmente son de nuevo préstamos concedidos a un plazo de tiempo muy corto, ya que se establece su devolución "en moneda metálica y no en vales reales ${ }^{20}$, en el mismo año, bien el 8 de septiembre para los efectuados en los primeros meses del año y en noviembre ( en las ferias de los Santos y de San Andrés) para los realizados de forma más tardía. Aunque no aparece ningún interés sobre los mismos en las escrituras de obligación, si que hemos apreciado que todos ellos tenían como base una hipoteca que otorgaba el deudor consistente en bienes raíces, los cuales en caso de incumplimiento con el prestamista pasarían a su propiedad mediante el sistema de ventas a favor del acreedor ${ }^{21}$. Éste más tarde cedería en arrendamiento estas tierras a los mismos campesinos que se las vendieron a cambio de una renta en grano. Por lo tanto, el negocio resultaba muy rentable consiguiendo no sólo fuertes beneficios sino también un relevante patrimonio raíz ${ }^{22}$. Y finalmente, tampoco descuidarán, caso de don Fernando Carrillo, el negocio del suministro del las tropas ${ }^{23}$.

José González Luna, don Pablo Flórez, don Fabián Ávarez Quiñones, don Bernardo Mallo, don Juan García, don Joaquín Ribas y don Miguel Fernández Gironda, (la cursiva es nuestra), con el objetivo de poder arrendar los derechos de puertas de la ciudad de León. Encargan de hacer la postura a don Pedro de Llamas poniendo a su disposición 86.289 reales, equivalentes a el 10\% señalado para hacer postura. Id., Ignacio Bayón y Luengo, Caja 1129.

19 Tanto don Fernando Carrillo como don Francisco Uriarte practican de forma muy frecuente esta actividad de préstamo de cereales sobre los año 30 del siglo XIX, especificando que los pagos se efectúen en monedas metálicas y no en vales reales. Id., Pedro Ballesteros Ginovés, Caja 1144.

${ }^{20}$ Ibidem.

${ }^{21}$ En enero de 1834 don Fernando Carrillo presta dinero a vecinos de Alija de la Ribera y en las escrituras de obligación aparecen por primera vez la relación de las hipotecas, generalmente tierras y huertas. Ibidem.

22 Nuestros personajes, particularmente don Francisco Uriarte y sobre todo don Fernando Carrillo, se dedicaron a este tipo de operaciones crediticias y en concreto en el año 1834 en el pueblo de Santa Olaja de la Ribera, se repartieron terrenos del concejo entre los vecinos y un número muy elevado de éstos van a vender rápidamente las tierras que les han tocado en el reparto a don Fernando Carrillo. Y posteriormente varios vecinos de forma conjunta (que se corresponden con los que han vendido sus tierras) las toman en arrendamiento el mismo año de 1834. Ibidem.

23 Así, en 1829, don Fernando Carrillo, obtendrá durante un año el remate del suministro de raciones de pan, paja y cebada para las tropas del ejército estante y transeunte en la capital y pueblos 


\section{LA FAMILIA CARRILLO-GONZÁLEZ: DEL COMERCIO DE TEXTILES A LAS FINANZAS.}

Como ya hemos señalado la familia Carrillo-González surge de la unión matrimonial de Fernando Carrillo con Paula González. A pesar de vivir en años de dificultades, sobre todo los de la Guerra de Independencia, el negocio familiar supo aprovechar las coyunturas positivas a partir de los años 20 y el balance de la riqueza patrimonial en el momento del fallecimiento del paterfamilias, en 1836, no puede ser más favorable y particularmente si lo comparamos con los momentos iniciales. De este modo, aunque sólo conocemos las aportaciones de la esposa a la nueva célula familiar (40.290 reales en dotales y parafernales) ${ }^{24}$ los bienes gananciales, descontadas las deudas en contra, ascenderán a la relevante cantidad de 409.281 reales, es decir el $85,5 \%$ del total patrimonial inventariado ${ }^{25}$.

Esta fortuna con escasas deudas, tan sólo se registra un pasivo de 29.250 reales, un $6,1 \%$ del activo patrimonial ${ }^{26}$, se ha obtenido, por una parte, mediante la venta al por menor de artículos variados (alpargatas, botones, etc.) y sobre todo textiles ${ }^{27}$ en su establecimiento de tienda abierta en la ciudad leonesa. Y por otra parte, a través de sus operaciones financieras que iban, como ya se ha analizado, desde el arrendamiento de rentas eclesiásticas y civiles $^{28}$ a las actividades crediticias de préstamos de cereales y sobre todo de dinero ${ }^{29}$. Además, también se interesará por el trato del ganado ${ }^{30}$.

de la provincia a los siguientes precios: 16 maravedíes las raciones de pan, 10 reales la fanega de cebada y 30 maravedíes la arroba de paja. Para ello otorga una fianza de 3.000 reales e hipoteca una casa en la calle Santa Cruz tasada en 10.000 reales. Lo curioso del contrato es que se estipula que si :”...el suministro excediese del triple quedaría sujeto el otorgante a la rescisión del contrato o a bajar los precios de los géneros...". Id., Juan de Dios Fernández, Caja 965.

${ }^{24}$ Id., Ignacio Bayón Luengo, Caja 1126.

${ }^{25}$ Ibidem.

${ }^{26}$ Ibidem.

${ }^{27}$ Donde sobresalen la venta de fibras textiles como el algodón y los pañuelos de pana, de hilo, etc. Ibidem.

28 Tiene compañía con don Pantaleón Ramos de varios "arriendos de Casas de Rey". Estas casas las daban en arriendo ya que en el mismo año de su fallecimiento don Fernando Carrillo declara que tiene arrendado con el referido Ramos varias Casas de Rey que importan unos 26.000 reales. Ibidem.

${ }^{29}$ Así, por ejemplo, a finales del año 1833 presta mediante el sistema de obligaciones la cantidad total de 65.615 reales a campesinos de los pueblos próximos a la ciudad de León. Id., Pedro Ballesteros Ginovés, Caja 1144

${ }^{30}$ En este asunto tiene compañía con Manuel García y Manuel Álvarez, en razón del trato de vacas y carneros por lo que le están adeudando cantidad de maravedíes. Ibidem. 
De este modo, si profundizamos en el estudio de la estructura de su fortuna nos encontramos con que es la riqueza mobiliaria la que tiene una mayor valoración, con un $64,7 \%$ del total de bienes inventariados y tasados ${ }^{31}$. No obstante, este mayor peso de la riqueza mobiliaria no se debe tanto a los bienes conectados con la actividad comercial, ya que los géneros almacenados sólo representarán un $16 \%$ en relación al activo patrimonial y un $24,8 \%$ de la riqueza mobiliaria, como a los conceptos relacionados con las operaciones financieras, las cuales significan un $40,5 \%$ en relación al activo y un $69,7 \%$ de la riqueza mobiliaria tasada. Además, la actividad financiera que más sobresale es la crediticia de cereales y particularmente de dinero con un $27,1 \%$. Por lo tanto, a nivel comparativo la similitud es mayor con la burguesía financiera, de mayor entidad leonesa, la familia FernándezLlamazares, que con la burguesía comercial tanto leonesa como de otras regiones ${ }^{32}$.

En un segundo lugar, con un $21,9 \%$ de la riqueza patrimonial, se sitúan las tierras de labor, adquiridas bien en la venta de bienes comunales de los municipios de comienzos del siglo $\mathrm{XIX}^{33}$ o bien como pago hipotecario de los préstamos realizados a los campesinos en granos y sobre todo en dinero. Así, mediante estos mecanismo consigue una explotación agrícola de unas 50 hectáreas, diseminadas

${ }^{31}$ Ibidem.

32 En la familia Fernández-Llamazares también la riqueza mobiliaria era la dominante con un $57,8 \%$ de la estructura de su fortuna, y dentro de la misma los conceptos relacionados con las finanzas eran los predominantes sobre los de la actividad comercial, aunque representaban un porcentaje más elevado, un $78,3 \%$, con la particularidad de que sobresalían las operaciones bancarias. En cambio, en la burguesía comercial las deudas a favor de la casa generadas por la venta de productos solía ser la partida de mayor relevancia, seguida del stock de productos almacenados. Ver BARTOLOMÉ, J.M. "Formación y desarrollo de la burguesía financiera en León...", "Comerciantes catalanes haciendo negocio en León: las familias Jolís y Bunell-Selva (1700-1850)" (en prensa), "La formación de un gran patrimonio mercantil-agrícola en León: la familia FernándezChicarro (1700-1850)" (en prensa), "Comerciantes de origen castellano en León: las familias Pablos Salán -Rodríguez y Hernández de Medina-Fernández (1700-1850)" (en prensa); ANGUlo, A. (2.000). Del éxito en los negocios al fracaso del Consulado: la formación de la burguesía mercantil en Vitoria (1670-1840). Bilbao. AzCONA, A. Mª (1996). Comercio y comerciantes en la Navarra del siglo XVIII. Pamplona. Franch, R. (1989). El capital comercial valenciano en el siglo XVIII. Valencia, 1989.

${ }^{33}$ Entre 1800 y 1820 se realizó un proceso de venta de propiedad comunales en León cuya mayor intensidad tuvo lugar durante la Guerra de la Independencia debido a los problemas financieros por los que atravesaban los ayuntamientos. De esta forma, fueron puestos en venta bienes comunales (casas, tierras) y don Fernando Carrillo junto con don José de Robles, compraron al concejo de Trobajo del Cerecedo 74 heminas ( 24,6 fanegas) de terreno comunal por un valor de 12.044 reales. LORENZANA, A., "Desamortización y transferencia de propiedad inmobiliaria en la ciudad de León a principios del siglo XIX”, en Revista de Estudios Humanísticos, p. 190. 
por los términos de los pueblos cercanos a la ciudad de León ${ }^{34}$, donde predominan con 41 hectáreas los cultivos de cereal de secano, aunque también hay de regadío, pero en la que tienen también cabida el viñedo, las praderas, los linares, etc. La escasa presencia de útiles de labranza y de animales de tiro, así como las escrituras de arrendamiento de tierras, nos inducen a pensar que se trata de tierras no trabajadas directamente por el propietario sino más bien dadas en renta generalmente a los mismos campesinos que se las habían vendido a cambio de una renta en grano.

También la nueva coyuntura de crecimiento demográfico y movimiento de la renta determinará que se interese por la compra de inmuebles urbanos, casas, etc., los cuales representarán un 13,2\% de la riqueza patrimonial ${ }^{35}$. Exceptuando la casa mesón situada en el pueblo de Villarente y valorada en 3.000 reales, el resto de los edificios urbanos, valorados en 60.476 reales $^{36}$, se localizan en la ciudad leonesa habiendo pasado a sus manos en algunos casos también por las ventas de bienes municipales mencionada anteriormente ${ }^{37}$.

Finalmente, nos sorprende la escasa importancia de su cabaña ganadera, donde a pesar de que entre sus múltiples ocupaciones figuraba el trato con el ganado, sin embargo, la valoración de la misma es de tan sólo 1.330 reales, lo que sólo representa un $0,2 \%$ de la estructura de su fortuna ${ }^{38}$.

Los bienes mobiliarios que nos informan sobre lo que podemos denominar las condiciones y estilo de vida destacan, en primer lugar, por su reducida valoración, ya que su tasación total es únicamente de 8.600 reales, es decir, el 2,8\% de la riqueza mobiliaria ${ }^{39}$. En segundo lugar, en su estructura interna son mayoritarios los bienes textiles, llegando a suponer casi la mitad de la valoración con un $48 \%$,

34 Trobajo del Cerecedo, Trobajo del Camino, San Andrés del Rabanedo, Azadinos, Alija de la Ribera, Castrillo de la Ribera, Navafría, Marialba, Alija de la ribera, Villaturiel, Mancilleros, Santa Olaja de la Ribera, Carbajosa, Villarente, etc. A.H.P.L., Pedro Balllesteros Ginovés, Caja 1144.

35 Porcentajes muy por debajo de los de los comerciantes banqueros de Cáceres, Melón, M.A., Los orígenes del capital comercial y financiero.., p. 121.

${ }^{36}$ A.H.P.L., Pedro Ballesteros Ginovés, Caja 1144.

${ }^{37}$ El notario Ginovés permuta una casa comprada de la venta de este tipo de bienes con Fernando Carrillo. Antonio Lorenzana Fernández, "Desamortización y transferencia...”, pág. 197.

38 Únicamente se inventarían una yegua y dos potros tasados en 1.330 reales. A.H.P:L., Pedro Ballesteros Ginovés, Caja 1144.

39 Porcentaje similar al de la otra familia financiera leonesa Fernández-Llamazares, pero la cantidad global de la valoración de los mismos es mucho mayor: 56.216 reales. BARTOLOMÉ, J.M., "Formación y desarrollo de la burguesía financiera...". 
pero dentro de los mismos no es la ropa destinada a la vestimenta persona $\mathrm{l}^{40} \mathrm{o}$ la de casa $^{41}$ la más predominante, sino la de cama con un $27,3 \%$, lo cual nos refleja de nuevo la escasa tendencia de la familia a la ostentación y al lujo. Modestia que, finalmente, se ve reflejada en la fuerte presencia y valoración del mobiliario muy tradicional de la casa ${ }^{42}$ y en el escaso valor que, al contrario de la burguesía financiera o comercial, se da a la tasación de los objetos de oro y plata (joyas, alhajas $^{43}$ ), especialmente a los de uso personal ${ }^{44}$, y a los objetos (cuadros, espejos, relojes, etc., ) que decoraban las paredes y en definitiva las estancias ${ }^{45}$.

A la hora de enfrentarse a la muerte y de realizar las disposiciones testamentarias tampoco apreciamos signos de ostentación por parte de don Fernando Carrillo, ya que lo que predomina es la sencillez y la escasa presencia de cláusulas de carácter religioso, dejando todo lo referente al entierro, hábito con que debe ser enterrado, misas, honras y cabo de año a la voluntad de su mujer. Y únicamente podría ser interpretado como un signo de ostentación, aunque también de caridad con el objetivo de poder salvar su alma, la cláusula que dispone que "se repartan entre los pobres mendigantes cuatro cargas de pan cocido en los días que tenga por conveniente dicha mi mujer..."46

Finalmente, tal como ya se ha señalado, cuando fallece don Fernando Carrillo, una vez que se descuentan del activo patrimonial, 478.821 reales, las deudas, 29.250 reales y los dotales y parafernales de la mujer, 40.290 reales, quedan como bienes líquidos gananciales 409.281 reales, los cuales se reparten entre los

${ }^{40}$ Donde si que aparecen ya las nuevas prendas del vestir masculinas: pantalones, chaquetas, etc., pero en general elaborados con fibras textiles tradicionales (lana, etc.) más que con las novedosas del algodón,etc. Así, por ejemplo, se inventarían tres pantalones todos de paño en 126 reales. A.H.P.L., Pedro Ballesteros Ginovés, Caja 1144.

${ }^{41}$ Las cortinas sólo son valoradas en 335 reales. Ibidem.

42 Con una tasación de 1.754 reales y un $20,4 \%$ del total de estos bienes se halla situado en tercer lugar de los mismos. No obstante, ni tan siquiera la sala principal de la casa tenía muebles más lujosos o novedosos ya que sólo destaca un canapé de nogal con asiento de paja valorado en 50 reales. Ibidem.

43 Considerados de vital importancia no sólo para dar solidez a la actividad comercial o financiera, sino también para poder hacer frente a posibles malos años en sus negocios. ANGULO, A., Del éxito en los negocios..., p. 318.

${ }^{44}$ Sólo figuran dos relojes de bolsillo, uno con caja de plata, tasados en 80 reales. Ibidem.

$45 \mathrm{Ni}$ tan siquiera son tan abundantes los cuadros de temática religiosa y únicamente encontramos cuatro espejos de medio cuerpo valorados en 160 reales y dos relojes de pared, uno de ellos valorado en 100 reales. Ibidem.

${ }^{46}$ Ibidem. 
dos esposos correspondiendo a cada uno la cantidad de 204.640 reales $^{47}$. De esta forma, cada uno de los dos hijos, Teresa y Salvador, recibirán en herencia bienes por la mitad de la hijuela paterna. Así, cada hijo hederá una cantidad total de 102.230 reales, no apreciándose, por lo tanto, ningún mecanismo de mejora en uno de los dos hijos ${ }^{48}$, a pesar de que el varón don Salvador Carrillo será el encargado de continuar el negocio familiar como nos lo demuestra el hecho de que en 1841 figure con antiguos colegas de su padre en el arrendamiento de las puertas de la ciudad de León.

\section{LA FAMILIA LLAMAS-GARCÍA ANTÓN: DEL COMERCIO DEL AGUARDIENTE A LAS FINANZAS.}

En un primer matrimonio Pedro Llamas contrae esponsales con Baltasar García teniendo tres hijos: Joaquín, Romualdo y Basilisa. Años más tarde, ante la muerte de la esposa, contrae un segundo matrimonio con Francisca Antón, a la cual concede el nuevo marido, por vía de dote, la cantidad de 6.000 reales $^{49}$, fruto del mismo fueron otros tres hijos: María Cruz, Juliana y Salvador

En el momento del fallecimiento del paterfamilias, en 1841, el balance patrimonial es claramente favorable ya que su activo asciende a casi medio millón de reales, 453.785 reales. Sin embargo, sobresale también el fuerte endeudamiento $^{50}, 128.940$ reales, un $28,4 \%$ sobre el activo, lo que trae consigo que el valor líquido patrimonial se reduzca a 324.845 reales $^{51}$. No obstante, la trayectoria en los negocios resultó ser muy positiva ya que hay que tener en cuenta que estos bienes fueron casi en su totalidad gananciales siendo las aportaciones al segundo matrimonio y sobre todo al primero de muy escasa cuantía. Así, durante el primer enlace los bienes gananciales fueron 108.320 reales y durante el segundo ascendieron a 204.343 reales descontadas las deudas en contra ${ }^{52}$.

Por lo tanto, de nuevo, la actividad comercial, centrada en la venta de licores y especialmente aguardiente, $\mathrm{y}$ sobre todo las financieras aportarán ingresos sustanciosos durante la primera mitad del siglo XIX a la familia analizada. Pero

${ }^{47}$ Ibidem.

48 Ibidem

${ }^{49}$ Id., Caja 1129

${ }^{50}$ La cantidad más importante la constituye con 117.516 reales por los diferentes ramos de la depositaria de propios. Ibidem.

${ }^{51}$ Ibidem.

52 Ibidem. 
más que el recurso al crédito de dinero o cereales la predilección serán los arrendamientos de rentas, formando compañías con otros socios, como ya se he indicado anteriormente, tanto de carácter civil: arrendamiento de los licores y aguardiente $^{53}$ o de las puertas de la ciudad, como eclesiástico: arrendamiento Voto de Santiago.

De ahí que si pasamos a un estudio pormenorizado de la estructura de su fortuna nos encontramos con que son los bienes mobiliarios los que conforman la partida más relevante su fortuna con un $69,2 \%$ de la misma ${ }^{54}$ y dentro de la riqueza mobiliaria serán los conceptos de mayor peso no los vinculados al negocio comercial de la venta de licores y aguardiente, cuyo stock sólo representarán el $2,4 \%$ en relación al activo ${ }^{55}$, sino el dinero en metálico existente, en caja, el 10,6\% del activo y especialmente las deudas a favor, que representarán el 29,5\% del $\operatorname{activo~}^{56}$. De tal forma, que si sumamos los dos conceptos últimos constituyen el $40,1 \%$ del activo y el $81,7 \%$ de los bienes mobiliarios tasados. Por lo tanto, aunque la complejidad de los negocios financieros es menor que la familia anteriormente estudiada, sin embargo, el esquema en la estructura de los bienes mobiliarios no puede ser más similar. Ahora bien, su interés por la adquisición de bienes raíces, sobre todo tierras, será menor que en la familia Carrillo-González. Así, por una parte, las tierras de labor ocuparán el tercer lugar en la estructura de su riqueza patrimonial con un $13,7 \%$ de la misma, destacando fundamentalmente las tierras, cuyas capacidades no especifica, existentes en el término de Grajal de Campos y del monasterio de Sahagún, tasadas en 40.800 reales, las cuales tampoco señala pero que seguramente fueron compradas durante el proceso desamortizador de Mendizábal. Y, por otra parte, los inmuebles urbanos, las cinco casas, con una valoración de 77.500 reales, se situarán en un segundo lugar de la riqueza patrimonial con un $17,1 \%$ de la misma. Sin embargo, esta alta valoración de las

53 Donde no sólo subarrendaban sino que también les servía para abastecer el almacén que compartía con don Francisco Uriarte y le permitía poder realizar la venta al por menor de aguardiente.

${ }^{54}$ Este porcentaje en realidad es ligeramente inferior ya que en él están incluidos 90.571 reales de dotes concedidas a sus hijos y que hemos optado por incluirlas en este concepto de bienes mobiliarios, ya que la mayor parte de la dote suele estar formada por este tipo de bienes pero también pueden tener cabida los raíces.

55 Sólo se inventarían 207 cántaras de aguardiente a 52 reales cántara, que hacen un total de 10.764 reales. Ibidem.

${ }^{56}$ Ibidem. 
casas no se debe tanto a un carácter inversionista ${ }^{57}$ como al hecho de que la casa propia de residencia y negocio tenga una valoración muy alta, 46.000 reales $^{58}$. Finalmente, frente a la familia objeto del anterior estudio la atención por la ganadería es nula.

A pesar de que su nivel de riqueza es inferior a la familia Carrillo-González, no obstante, la valoración que se realiza en su inventario postmortem de los bienes que conforman las condiciones y estilo de vida es muy superior: 27.724 reales, lo que significará el $12,4 \%$ de la riqueza mobiliaria frente al $2,8 \%$ de la anterior familia. Además, se trata de una cantidad nada desdeñable que se sitúa incluso por encima de la que destinan sus convecinos y ricos comerciantes, ejemplos de las mayores fortunas leonesas, don Ramón Selva y don José Fernández Chicarro ${ }^{59}$.

Es más, si nos adentramos en el estudio de su estructura interna serán los bienes más conectados con la ostentación personal los que tendrán una mayor valoración. Así, el primer lugar lo ocupan los textiles, la ropa, con un 37,7\%, pero sobre todo la ropa personal y no la destinada a la cama o a la casa. Además, en la ropa de vestimenta personal son muy frecuentes las nuevas prendas de vestir sobre todo masculinas (pantalones, chaquetas, chalecos), aunque tampoco faltan las femeninas: vestidos, elaboradas con la también innovadora materia prima del algodón $^{60}$. Y el segundo lugar, con un $36,7 \%$, será para la valoración de los objetos de oro y plata, donde de nuevo más que los de uso doméstico, cubertería, serán las joyas y alhajas destinadas al uso personal las predominantes ${ }^{61}$. Indudablemente, como ya conocemos, la posesión de este tipo de bienes de oro y plata eran fundamentales para el prestigio del negocio y para poder hacer frente a posibles eventualidades, pero como en la familia Carrillo- González se podían concentrar en

${ }^{57}$ Como se ha apreciado en Cáceres con los comerciantes banqueros, favorecida por evolución demográfica, el movimiento de la renta y la legislación favorable de los arrendamientos urbanos. Ver MEÓN, M.A., Los orígenes del capital comercial y financiero..., p. 121.

58 A.H.P.L., Ignacio Bayón Luengo, Caja 1129

${ }^{59}$ Ver artículos de BARTOLOMÉ, J.M., "Comerciantes catalanes haciendo negocio en León ...", "La formación de un gran patrimonio mercantil-agrícola...".

${ }^{60}$ Ver trabajos grupo investigación coordinado por el profesor Bartolomé Yun CASALILLA, Consunmo y comercialización de textiles en Castilla y Cantabria, 1750-1914. Y en particular, BARTOLOMÉ, J.M.(2004). El tránsito al crecimiento económico moderno en León. Condiciones de vida y pautas de consumo en La Bañeza y Astorga (1750-1850). León.

${ }^{61}$ De la tasación global de 10.284 reales la mayor cantidad, 6.220 reales, corresponden a cadenas de plata, relicario de oro con diamantes, pendientes de diamantes, etc., destacando un alfiler de brillantes valorado en 1.000 reales y un collar de diamantes con pendientes de lo mismo en 3.000 reales. A.H.P.L., Ignacio Bayón Luengo, Caja 1129 
la piezas de cubertería de la casa y no tanto en el adorno personal. Incluso, este mayor gusto por el lujo se refleja también en la decoración de sus estancias, ya que con un $10,2 \%$ se acercará mucho a la valoración de una partida de bienes que siempre se situaba muy por encima, la del mobiliario de la casa. De este modo, junto con las cortinas ${ }^{62}$, cornupias y los abundantes cuadros de temática religiosa, también cubren las paredes espejos y relojes ${ }^{63}$. Además, no hay que olvidar que el propio mobiliario de la casa es muy moderno, ya que figuran piezas como los sofás, tocadores y las cómodas. En definitiva, unas condiciones y estilo de vida con ciertas dosis de confort y ostentación personal, a la que no es muy dada la burguesía comercial y financiera leonesa, pero en ningún caso llegando a rayar en un lujo exagerado ${ }^{64}$.

Esta preocupación por la apariencia social se aprecia también a la hora de examinar sus últimas voluntades, ya que resulta muy curiosa la cláusula que estipula que su entierro "...sea el correspondiente a la clase que ocupa en la sociedad...", dejándolo a la voluntad de su esposa ${ }^{65}$.

En cuanto a las posibles estrategias de cara a sus hijos no apreciamos las de carácter matrimonial, una de las hijas del primer matrimonio, María Cruz, se casará con don Pablo Flórez, y las de tipo hereditario se concentran en las mejoras de muy escasa cuantía que hace a los tres hijos del segundo matrimonio. Así, los tres hijos del primer matrimonio heredarán bienes por un total de 42.297 reales de su legítima materna y paterna y los tres del segundo matrimonio recibirán cantidades ligeramente muy distintas, ya que a los 24.244 reales de la hijuela paterna se suman 10.000 reales que se conceden al hijo varón, don Salvador, por vía de mejora para ayudarle en la continuación de su carrera ${ }^{66}, 8.213$ reales que concede por la misma vía a su hija doña María Cruz y 3.520 reales a su otra hija menor de

${ }^{62}$ Donde ya aparecen las de algodón y de colores. Ibidem.

${ }^{63}$ Se tasa un reloj de música en 2.500 reales. Ibidem.

${ }^{64} \mathrm{Al}$ igual que sucedía con la burguesía vitoriana o valenciana. ANgulo, A., Del éxito en los negocios..., p. 324. FRANCH, R., El capital comercial...

${ }^{65}$ Las abundantes claúsulas religiosas se reducen en este caso a que "se digan dos misas votivas de veinte reales cada una a Ntra Sra Del Carmen y a la del Mercado en sus altares respectivos...". y a la ya mencionada de que " Quiere que el entierro sea el correspondiente a la clase que ocupa en la sociedad a entera voluntad de su esposa y testamentarios sin que sea necesario hacer sobre ello más advertencia”. A.H.P.L., Ignacio Bayón Luengo, caja 1.129.

${ }^{66}$ Además, se estipula también "...que no se le cuente nada de lo que hasta ahora haya gastado, aún cuando resulte de asientos". Ibidem. 
edad doña Juliana ${ }^{67}$. Por lo tanto, asistimos a un reparto igualitario donde la fortuna que ha constado tanto conseguir se fragmenta tras la muerte del paterfamilias, en los años cuarenta del siglo XIX, entre sus seis hijos, no apreciándose, además, la continuación del negocio familiar en la figura de algunos de sus descendientes.

\section{CONCLUSIONES.}

De lo expuesto en las páginas anteriores nos interesa remarcar cuatro conclusiones: En primer lugar, las familias analizadas constituyen un ejemplo de la burguesía que combina las actividades comerciales y financieras durante la primera mitad del siglo XIX, pero teniendo un mayor peso en la estructura de sus negocios las operaciones de carácter financiero. En segundo lugar, tal como hemos podido apreciar, este tipo de actividades financieras no serán de gran escala (letras de cambio, vales reales, etc.) y estarán muy distantes de las de carácter moderno ${ }^{68}$ y en cambio se enmarcarán más en las típicas del Antiguo Régimen, aprovechando las posibilidades que éste ofrecía: arrendamiento de rentas eclesiásticas y civiles y préstamos de cereales. En tercer lugar, serán este tipo de operaciones financieras más que el comercio las que les proporcione un claro éxito económico con activos patrimoniales próximos al medio millón de reales, siendo la mayor parte de su fortuna conseguida de forma ganancial. Sin embargo, estas ganancias no las van a destinar a inversiones industriales ni tan siquiera a ampliar y mejorar su comercio o sus operaciones financieras, sino que su objetivo principal será la compra de bienes raíces desamortizados, sobre todo tierras, de las cuales sólo les interesarán las rentas de las mismas más que su explotación. De ahí, que se aprecie de nuevo en este comportamiento la escasa asunción de riesgos y una mentalidad más rentista y típica del Antiguo Régimen de estas familias. Y finalmente, tampoco hemos observado estrategias matrimoniales o hereditarias encaminadas a conseguir una prolongación del negocio familiar en la figura de uno de los herederos. En definitiva, burguesía financiera típica del Antiguo Régimen a pesar de vivir en la primera mitad el siglo XIX.

${ }^{67}$ Ibidem.

${ }^{68}$ Como las desempeñadas por la familia banquera Fernández-Llamazares. Ver BARTOLOMÉ, J.M., "Formación y desarrollo de la burguesía financiera en León...". 
Cuadro 1.Balances patrimoniales (reales)

\begin{tabular}{lcccc}
\hline & Año & Activo & Pasivo & Líquido \\
\hline Fernando Carrillo & 1836 & 478.821 & 29.250 & 449.571 \\
Pedro LLamas & 1841 & 453.785 & 128.940 & 324.845 \\
\hline
\end{tabular}

FUENTE: A.H.P.L. (Protocolos Notariales)

Cuadro 2. Conceptos relacionados con la actividad financiera (\% relación al activo) (reales)

\begin{tabular}{lrrrr}
\hline & \multicolumn{2}{c}{ Fernando Carrillo } & \multicolumn{2}{c}{ Pedro Llamas } \\
\cline { 2 - 5 } & Reales & $\%$ & Reales & $\%$ \\
\hline Dinero en efectivo & 59.158 & 12,3 & 48.100 & 10,6 \\
Deudas a favor (préstamo de dinero, cereales) & 12.670 & 2,6 & - & - \\
Deudas a favor (sin especificar) & 117.542 & 24,5 & 134.124 & 29,5 \\
Deudas a favor (rentas diezmos arrendados) & 5.375 & 1,1 & - & - \\
\hline
\end{tabular}

FUENTE: A.H.P.L. (Protocolos Notariales)

Cuadro 3. Riqueza patrimonial (En reales y porcentajes sobre el valor del stock de bienes inventariados)

\begin{tabular}{lrrrr}
\hline & \multicolumn{2}{c}{ Fernando Carrillo } & \multicolumn{2}{c}{ Pedro Llamas } \\
\cline { 2 - 5 } & Reales & $\%$ & Reales & $\%$ \\
\hline Tierras de labor & 105.266 & 21,9 & 62.300 & 13,7 \\
Viviendas y dependencias complementarias & 63.476 & 13,2 & 77.500 & 17,1 \\
Ganadería & 1.330 & 0,2 & - & - \\
Bienes mobiliarios & 308.749 & 64,7 & 223.414 & 69,2 \\
\hline
\end{tabular}

FUENTE: A.H.P.L. (Protocolos Notariales)

Cuadro 4. Riqueza mobiliaria (En reales y porcentajes sobre el valor del stock de bienes inventariados)

\begin{tabular}{lrrrr}
\hline & \multicolumn{2}{c}{ Fernando Carrillo } & \multicolumn{2}{c}{ Pedro Llamas } \\
\cline { 2 - 5 } & Reales & $\%$ & Reales & $\%$ \\
\hline Ajuar, mobiliario, joyas, etc. & 8.600 & 2,8 & 27.724 & 12,4 \\
Muebles de la tienda & - & - & 2.177 & 0,9 \\
Géneros comercio & 76.736 & 24,8 & 10.764 & 4,8 \\
Deudas a favor & 148.342 & 48 & 134.124 & 60,1 \\
Dinero efectivo & 59.158 & 19,1 & 48.100 & 21,6 \\
Rentas bienes raíces & 8.186 & 2,6 & - & - \\
Útiles agrarios & 1.320 & 0,4 & 498 & 0,2 \\
Productos de la despensa & 6.407 & 2,3 & 27 & 0 \\
\hline
\end{tabular}

FUENTE: A.H.P.L. (Protocolos Notariales) 
Cuadro 5. Condiciones o estilo de vida (En reales y porcentajes sobre el valor del stock de bienes inventariados)

\begin{tabular}{lrrrr}
\hline & \multicolumn{2}{c}{ Fernando Carrillo } & \multicolumn{2}{c}{ Pedro Llamas } \\
\cline { 2 - 5 } & Reales & $\%$ & Reales & $\%$ \\
\hline Decoración de la casa (objetos religiosos) & 691 & 8 & 2.835 & 10,2 \\
Mobiliario casa & 1.754 & 20,4 & 3.093 & 11,1 \\
Útiles cocina (menaje, loza fina) & 891 & 10,4 & 1.040 & 3,7 \\
Ropa personal & 1.124 & 13 & 6.937 & 25 \\
Ropa cama & 2.347 & 27,3 & 2.718 & 9,8 \\
Ropa casa & 666 & 7,7 & 817 & 2,9 \\
Joyas & 1.127 & 13,2 & 10.284 & 36,7 \\
Libros & - & - & - & - \\
\hline
\end{tabular}

FUENTE: A.H.P.L. (Protocolos Notariales)

Cuadro 6. Dinámica reproducción económica familiar a partir de los bienes aportados al matrimonio por los esposos (reales)

\begin{tabular}{lrrrrrrr}
\hline & $(1)$ & $(2)$ & $(3)$ & (4) & (5) & (6) & (7) \\
\hline Fernando Carrillo & 0 & 40.290 & 40.290 & 409.281 & 478.821 & 85,5 & 8,4 \\
Pedro Llamas y 1 $1^{\mathrm{a}}$ mujer & 0 & 0 & 0 & 108.320 & 108.320 & 100 & 0 \\
Pedro Llamas y 2 $2^{\mathrm{a}}$ mujer & 54.160 & 5.490 & 59.650 & 204.343 & 453.785 & 45 & 13,1 \\
\hline (1) Bienes aportados esposo; (2), Bienes aportados & esposa; (3), Total ambos (A); (4),
\end{tabular}

Bienes Gananciales (B); (5), Total patrimonial (activo) (C); (6) $\% \mathrm{~B} / \mathrm{C}$; (7) $\% \mathrm{~A} / \mathrm{C}$

FUENTE: A.H.P.L. (Protocolos Notariales) 